Personal and professional development (or use of self) in social educator training. An experienced based on reflective learning

Maria Pallisera, Judit Fullana, Josep-Miquel Palaudarias, Mercè Badosa

IRE, University of Girona (Spain)

maria.pallisera@udg.edu

judit.fullana@udg.edu

josep.palaudarias@udg.edu

merce.badosa@udg.edu

University of Girona

Pl. St. Domènec, 9

17071 Girona

Spain 


\title{
Personal and professional development (or use of self) in social educator training. An experienced based on reflective learning
}

\begin{abstract}
Working on use of self with professionals in social education from the initial training stage onwards is often deemed a necessary contribution to their personal and professional development. Despite this, it is difficult to find references to programs and experiences that have been undertaken from this perspective. In this article we present a recent experience from a university in Catalonia (Spain) which aimed to work on self-knowledge and professional identity through implementation of the reflective learning model prior to students' practical work experience. The first section of the article is dedicated to contextualizing the experience of training social educators in Spain. A theoretical framework is then provided, including a description of course content, methodology and assessment, and finally the experience is assessed by noting strengths and weaknesses detected in the process.
\end{abstract}

\section{Keywords}

Social Work Education, Personal and Professional Development, Reflection, Course Design 


\section{Personal and professional development (or use of self) in social educator training. An experienced based on reflective learning}

\section{Introduction}

Reforms introduced to adapt Spanish university studies to the European Higher Education Area have brought with them an in-depth review of education and training. This, in turn, has led to weaknesses being detected and subsequent research into new approaches aimed at the integrated training of social education professionals. One of the strategies to have been implemented is the incorporation of work aimed at personal and professional development, in which reflective learning plays a key role. In this article we describe an experience undertaken with students in the second year of their Social Education degree course at the University of Girona. The experience consists in creating an opportunity for students to work on self-knowledge and professional identity before they begin their practical work experience. The first section of this article contextualizes the experience of training social educators in Spain. We then continue by taking a more in-depth look at the basic characteristics of the experience and the methodology followed. Finally, we assess the experience by analyzing strengths and weaknesses detected in the process. We believe that this experience, initially aimed at students of Social Education in Spain, could be generalized to the education and training of Social Work Educators in an international context.

\section{The context of the experience. Training social educators in Spain}


Social educators, social workers, care workers, special educators, youth workers, community workers and cultural animators are all common names given to the social professions in different countries around Europe (Kantowicz, 2007). A comparison of different types of social work is very complex due to the different factors involved; that is, the origin and evolution of social work in each context, how education and training is structured, the type of work and duties exercised by different professionals, and professional recognition itself (Meeuvisse \& Swärd, 2007). In Spain, the professions of social assistant (in Spain named social worker) and social educator are those which are most clearly identified as social professions. The experience we develop in this article is focused on the training of social educators. As we pointed out in another article (Fullana et al 2009), social educators work in very diverse fields in Spain. Traditionally, three main areas are considered: specialized education, which works with vulnerable groups in a situation of exclusion; community development, aimed at promoting socio-cultural events and social participation among different groups; and adult education, that is, educational activities conducted at professional-occupational training centers, and local training plans, services and programs for refugees and ethnic minorities. The most common type of work done by social educators is educational support for individuals and groups in the social services system. Most carry out direct care tasks (day care and residential care) in combination with others such as designing programs or projects and monitoring them, assessment tasks, and team work coordination. A more detailed analysis of the different roles of professionals in the social sphere in Spain can be found at Fullana et al, 2011.

Social educator training is relatively recent in Spain when compared with the educational and professional careers of professionals in the same field in other 
European countries. The Spanish Civil War (1936-39) and forty years of dictatorship meant that the country did not have a public social services system until the beginning of the 1980s. In 1991, the Spanish Ministry of Education approved the Social Education degree course. Its incorporation as a university subject represented an important step in establishing the profession, leading to its social recognition (Fullana et al, 2009).

Social education work is set against a continuously evolving context. The reality of the profession suggests the need to develop education and training that, as Fook points out (2007), assumes uncertainty as an inherent element and integrates it more as an opportunity than as a threat. The reflective learning model is, in our view, an appropriate focus for contributing to the personal and professional development of future social educators, avoiding technical teaching and allowing students to learn to face situations of uncertainty and manage the risks of their future profession with autonomy, creativity and professionalism.

This model also constitutes a very adequate framework for helping future professionals to develop strategies that foster anti-discriminatory practices. Knowledge of oneself and how experiences, feelings, emotions, values and knowledge affect professional behavior constitutes an important instrument for carrying out professional work and guaranteeing users' rights (Arandia et al, 2012). Ward (2008) points out that such work is necessary because inappropriate action by professionals in the service can lead to users lacking control over their own lives and futures.

It is important for students to have adequate and sufficient opportunities to explore their thoughts, feelings, values, knowledge and experiences before beginning their work placement (Harrison and Ruch, 2007; Harrison, 2009; Dempsey et al., 2001; 
Reupert, 2009). However, as stated by Chapman et al. (2004) and Ward (2008), there is a lack of recent research into the question of how to educate practitioners in this aspect of their practice. Of the few studies that do exist, those that stand out are Chapman et al (2004), Lordan et al (2009), Dempsey et al (2001) and Ward (2008). Chapman et al. (2004) describe a seven-week course (What We Bring to Practice) designed to help students address difficult questions on use of self and critical thinking. The course explored the areas of self-revelation, boundaries in the professional relationship, race and ethnicity in the care relationship, and family origins through the viewing and analyzing of films showing different perspectives of user and professional interaction, readings and role plays. Lordan et al. (2009) present an experience which focuses on developing self-awareness in a creative environment based on constructing masks. Dempsey et al. (2001) present a module aimed at working on personal identity during the first two years of training, the purpose of which was to allow students to develop self-awareness and work in a safe environment to explore who they are and how they feel in a small group. The experience described by Ward (2008) consists of a sequence of seminars related to work on use of self, focusing on being a person within a group, use of self in preparing for practice, and use of self in practice.

In this article we describe an experience undertaken with students in the second year of their Social Education degree course at the University of Girona (Spain). The experience consists in creating an opportunity for students to work on selfknowledge and professional identity before they begin their practical work placement. After completing our own experience, we feel that its publication might contribute to partially filling the vacuum of information regarding training experiences in this area. Concretely, the principal contributions of our research are 
as follows: firstly, the experience contributes to acknowledging the inherent complexity of identifying steps to guide students gradually towards a reflective position. Secondly, it shows how different activities closely linked to narrative methods can be used to engage students in the exploration of self, increasing selfawareness and improving reflective thinking and learning.

\section{The experience: A module for personal and professional}

\section{development}

The aim of the experience is to further students' personal and professional development, helping prepare them to face situations of uncertainty and manage risks inherent in their profession. The experience takes place within the context of an annual module in the second year of the course, before their practical work placement. It is framed within the perspective of reflective learning and uses narrative as a central axis for the different teaching and learning activities.

Since Dewey's conceptualization of reflection as an essential component of learning, many authors have underlined the importance of this approach in training social educators and social workers (Lay and McGuire, 2010). Reflective skills are now considered essential for professionals and there is therefore a need to find effective ways of teaching and learning these tools (Knott, 2010). Different approaches have contributed to constructing the concept of reflective learning. One derives from the analysis of and reflection on the concept of "reflection" itself: What does reflection consist of? What role does reflection play in practice? Rogers (2001) reviewed contributions by different authors in relation to the steps involved in the reflective 
process. Another approach places emphasis on learning from experience, the role this experience plays in learning and knowledge acquisition. One of the most influential authors in this respect is Kolb (1984), whose theory of experiential learning posits learning to be the creation of knowledge through the transformation of experience. The two approaches converge in the concept of "reflective learning", understood as a process that leads to reflection on all sources of knowledge that may contribute to understanding a situation, including personal sources and experience. Of these sources, the fundamental role of experience stands out and emphasis is placed on how reflection based on experience leads to the construction of knowledge and learning.

From the perspective of reflective learning, narrative has significant potential as a support for personal and professional development (Frost, 2006; Harrison, 2009; Lehman, 2006; Taylor, 2006). Telling stories or relating situations provides a starting point from which to explore knowledge and theory, develop new ideas on different issues and situations and, ultimately, act. Although acknowledging that its use in higher education is not very widespread (Fook et al, 2006; Jenkins and Londsdale, 2007; McKillop, 2005), different authors advocate the incorporation of narration in developing reflective thinking (Lehmann, 2006 and Harrison, 2009). Tomkins (2009) highlights its role as a means of communicating with others and making our voice heard in the world; McKillop (2005) points to the fact that the stories we tell say more about how we perceive situations than how things really are. Taylor (2003 and 2006) states that we use narrative in both the personal and professional spheres in order to structure situations and activities, and in doing so we highlight our identity. Frost (2006) asserts that stories about our everyday life allow us to reflect more profoundly on how we act in relation to others. Paquin 
(2006) postulates that the stories people tell reveal how they see themselves and others, the problems they perceive in their lives and the significance of these problems. Thus, our way of seeing things, understanding the world, shaped by our experiences, is reflected in our narratives, which means that we can use them to work on both our identity and our personal and professional development. Narration constitutes the central axis of the teaching activities which, developed from the perspective of reflective learning, provide the focus for the experience we describe below.

\subsection{Content}

The module addresses different aspects related to the analysis and construction of personal life paths, looking in greater depth at the reasons behind individuals' actions and expectations, and how these relate to professional practice. One of the aims of the module is to help students analyze personal characteristics that foster non-discriminatory professional practices and respectful professional relationships that take users' rights into account. Specifically, the content worked on in the module is distributed into three interrelated thematic units or blocks, as follows:

Thematic block 1: Constructing personal life paths - experiences and contexts. Aimed at:

- Understanding how experiences interrelate in different contexts to influence how personal life paths are shaped.

- Analyzing how educational experiences affect one's actions, expectations and relationships.

- Exploring personal motivations for wanting to help or look after others. 
Thematic block 2: The relationship, a working tool for educators. Aimed at:

- Exploring skills that lead to the construction of honest relationships in professional life: listening, empathy as a basis for relationships.

- Analyzing different issues in professional relationships: appearance and first impressions and how they condition the relationship; limits or boundaries in professional relationships; personal prejudices that condition relationships with users.

Thematic block 3: Exploring professional identity. Aimed at:

- Developing the ability to analyze and understand one's own cultural competence: how we transmit stereotypes, sexism and prejudicial elements.

- Exploring the personal image of preferred professional identity and what has contributed to shaping it.

$\circ$ Identifying and analyzing some of the underlying assumptions attributed to professionals in the field.

\subsection{Methodological planning: sequencing and types of teaching activities}

The module is worth 6 annual ECTS credits ${ }^{1}$, equivalent to 150 hours of student work. Fifty hours of classe are developed throughout the course, with students

\footnotetext{
${ }^{1}$ European Credit Transfer and Accumulation System (ECTS) is a standard for comparing the study attainment and performance of students of higher education across the European Union and other collaborating European countries. One academic year corresponds to 60 ECTS credits that are equivalent to $1500-1800$ hours of study in all the countries and is used to facilitate transfer and progression throughout the Union.
} 
organized into groups of 12 or 13 and doing fifteen two-hour group sessions and two individual sessions on the course. Each group has a tutor/facilitator.

The use of reflection as a basis for working on personal and professional development is a novel approach for both tutors and students. In their previous education, students have not generally sufficiently developed the skills to reflect on the meaning of personal experiences; neither have they done sufficient work on exploring their emotions and the role these and their own personal experiences might play in their professional identity. One important challenge, therefore, is to equip students with tools for developing their reflective competence/ability.

Two basic decisions were taken in designing the program. The first was to sequence activities in such a way that those done at the beginning of the module are used to help students assimilate reflective learning methodology. Boud (1999) and Reupert (2009) warn of the error of organizing education as a closed list of exercises in which working guidelines are rigidly implemented, when the aim is actually to promote reflective learning. This first decision therefore allowed us to plan an open list of activities sequenced to progressively facilitate more in-depth work on reflective learning. The teacher provides more guidance at the beginning of the course and the dynamics of each group dictate the actual work undertaken.

The second decision consisted in using various strategies to stimulate reflective narration. Combining activities based on reflective written texts, including some with a visual component (photographs, drawings, videos, or visual texts), offers multiple opportunities for exploring the meaning of one's own experiences and 
subsequent reflective analysis. Multiple texts allow students a more in-depth understanding of the scope and influence experiences have on emotions, ways of understanding the profession and establishing relationships in the social education environment.

Figure 1 shows the different types of activities used on the course. One example is given for each. Below that is a description of each activity with details of how it is conducted with students.

\section{(Fig.1. Types of activities done on the course)}

\section{- Reading and analysis of life stories as a basis for reflection.}

Reading, analysis and reflection on life stories constitute the first activities in the module. The aim here is to familiarize students with analyzing narratives from a reflective viewpoint and provide them with strategies for this type of work. Activity A is an example of this.

Activity A: This is one of the first activities students do and is based on first-person narratives -life-stories- taken from materials related to social education work. Particular emphasis is placed on exploring the meaning of the story on a personal level. Students' own narratives show that they find it difficult to go beyond the descriptive level and connect their life story with their personal experiences and theoretical issues related to social work. Notwithstanding this, it is an activity that allows students to experiment with and understand the type of work that will be required of them in this module. As is made clear from the evaluation questionnaire students complete at the end of the course, they acknowledge it as being meaningful as it shows them how life experiences shape personal and professional pathways: 
"Personally, I consider the life story and genogram activities to be the ones to have led to most personal reflection and therefore those which helped me understand how our past life experience conditions our future.” (Student 1)

"The life stories helped me to see how difficult and complex some people's lives can be and motivated me to get involved in situations and provide these people with help.” (Student 2)

\section{- Narrative writing: reproducing personal stories/experiences.}

As the module progresses, different exercises require students to demonstrate the relationship between their own personal experiences and their actions, expectations and relationships. The aim is to use narrative writing as a means of helping students to explore their personal motivations for wanting to help or look after others. One of the first activities they do after working on life stories is activity B:

Activity $B$ : This consists in constructing a family genogram and working on reflective exercises based on this. After constructing the genogram, students are told to produce a written narrative which reflects on the effects of the family system on personal development, and specifically on their interest in becoming a social educator. This activity provides students with the opportunity to anticipate problems related to the revealing of personal situations in their professional life. Their reflections on the effect their family system and family relationships have had on their interest in becoming a social educator is subsequently contrasted with the written narrative they produced for their educational pathway. In this exercise, students reflect on how the educational models and relationships they have experienced have helped to shape their view of education. Most students comment that constructing the genogram helped to raise their awareness of the influence their family has had on them: 
“Constructing the genogram allowed me to learn through my family. I learnt that the family system is very influential, but not decisive." (Student 3)

With regard to the narrative on their educational pathway, students state that reflecting on this provides them with the opportunity to connect their educational experiences with their current view of education.

\section{- Use of graphics/drawing as a basis for stimulating reflective narratives}

The use of visual texts (photographs, drawings, images, etc.) is particularly useful when participants have difficulties expressing feelings and emotions (Keats, 2009). According to Osmond \& Darlington (2005), pictorial representations constitute an excellent means of stimulating discussion on the relationship between knowledge and practice and they recommend such activities in their research into methods favoring critical reflection. Student drawings or diagrams are used as an instrument for fostering reflective narration at different times throughout our course.

Activity $C$ : Reflective analysis on personal life path: "The river of my life". This consists in producing a drawing that represents one's personal path through life, symbolized in the drawing of a river with the most significant events, people and/or situations marked on it. This provides a visual overview of each person's values, beliefs, life experiences and representations. The sum of the elements that emerge helps students to reinterpret their own path. 
Activity D: Projected personal/professional future. Related to the previous activity, this aims to project their future after taking an in-depth look at their personal life path. It consists in graphically depicting their desired future path on a personal, family and work level, attempting to provide a graphic response to the question: "How would you like to see yourself 10 years from now on a personal, family, and professional level?"

As Osmond \& Darlington (2005) point out, students often initially protest when asked to do drawing activities but then become very involved in the activity and evaluate participation in these activities as enjoyable. In our experience, we found that drawing does in fact stimulate narration and helps students to clarify the experiences, people and situations that have been particularly significant in their lives:

"The "river" activity was very interesting because it made me reflect on aspects of my life which I thought I had accepted, but by reviving them I realized that wasn't true. It helped me to identify significant people in my life and think about how they had influenced me." (Student 4)

\section{- Analysis of professionals' oral narration of their experiences}

One of the main activities on the second half of the course is the design, implementation and reflective analysis of an interview with an experienced social educator.

Activity E: The aim of this activity is to use a practitioner's narrative to explore some of the main challenges related to working in the profession. The students prepare the interview script as a group and then conduct the interview. They then produce an individual reflective analysis after obtaining the view of the 
professionals themselves. Students produce a written narrative on the impact the interview has had on their view of the profession and the relationship with users and other professionals. They are also asked whether they would like to work in the center where the educator they have interviewed works and what they think they could contribute to it. Finally, they are told to highlight what they have learned from the interview on a personal level. The following are some excerpts from the assignment:

"Will I be able to separate my personal life from my professional life? Will I be able to maintain the desire I have now to work in the field of social education?" (Student 5)

"The interview with John (social educator at a residential care center for children) helped me think about things which are fundamental if I want to become a social educator in the future: coherence in my actions and those of the educational team in general, continuous training, emotional stability, the importance of communication within the team and, above all, trusting the people you are working with" (Student 6)

The activity also helps students to evaluate possible areas for professional development, or future professional practice. For exemple, the following excerpt show the reflection of a student after interviewing a social educator who works in a center for homeless people:

"I think I would find it difficult to work in a center like that (a center for homeless people). I think I could learn a lot there, but I'm put off by the fact that the people who use this resource are in a situation where drugs and mental illness are very present. That said, the relational dimension you can establish does interest me. I think the center could favor the creation of spaces for sharing learning and experiences, where you can work on the basis of dialogue and expression, which are of particular interest to me.” (Student 7) 


\section{- Viewing clips and films}

The viewing of films, whether whole or in parts, is a tool which is often used in social education training, as highlighted by Downey et al (2003). This activity facilitates meaningful learning and stimulates knowledge and the development of attitudes, emotions and values (Liles, 2007; Shdaimah, 2009). It also motivates students to get involved in a case or simulated situation, helping them to position themselves as a professional. We use a complete film throughout the course, but opt to view only individual fragments or clips, considering, as Liles does (2007), that this allows specific aspects to be analyzed in more depth without analysis being conditioned by the plot of the film.

Activity F: Viewing and analyzing fragments of films. Different fragments are selected to allow for the analysis of relationships and situations of empathy, exploring different models of relationship and analyzing the difficulties of establishing the educational relationship. Films used in this activity are My name is Joe, Ladybird, Ladybird, The Dead Poets' Society, National 7, Coming Home, and A Child is Waiting, among others. We work on topics related to the educational relationship: the helping relationship, first impressions, the professional's prejudices towards the client, etc.

The experience has shown us that using fragments of films helps students to situate themselves quickly within the context of the subject matter. These activities have been especially useful in studying interpersonal relationships in greater depth. The films were used to develop role-play situations in which students transformed the relationships viewed in the fragment by reflecting on skills they might use to act in these situations. 


\subsection{Assessing learning}

- Students' learning is assessed via a portfolio of the different learning activities they have done on the course.

Two individual reviews are conducted of the portfolio. In the first tutorial, the tutor gives students their assessment and offers them guidelines for improving their work and advice on how to benefit more from reflective learning. In the second individual tutorial, the work done during the second part of the course is reviewed and the tutor provides students with feedback on the different activities and overall progress of their portfolio. Together, they assess the student's progress throughout the course.

\section{What have we learnt from the experience? Evaluation and challenges}

During the 2010-11 and 2011-12 academic years, 98 students in the second year of their Social Education degree participated in the experience. They were divided into four groups, each with their own tutor. The teaching staff monitored the experience intensively by keeping a diary of how each session progressed. This text helped us to retain evidence of the incidents that took place and evaluate the strengths and weaknesses of the experience. The students also participated in evaluating the experience via two individual sessions in which they were encouraged to assess their own learning, review their individual aims and formulate strategies for improvement. In addition to this, questionnaires were handed out at the end of the first semester and at the end of the year to collect students' opinions on the aims, 
content and activities of the module, as well as their perceptions of the learning that had taken place.

On the basis of this intensive follow-up, some ideas have arisen that must be taken into account for future courses. Firstly, students evaluate the learning achieved on the course positively. Their reflections and responses reveal a tendency to consider that the course has helped them to understand the relationship between their life experiences and personal actions and improve their capacity for reflection:

"I've learned to analyze different situations and reflect on them. (...) I think it has helped me to analyze myself and others and to improve my skills and become more aware”. (Student 5)

They value the fact that they have achieved greater personal understanding of their preferred professional identity, learned to question their own actions and realized the importance of raising doubts:

"Personally, I rate the activity of the written narrative regarding professsional identity positively, as it helped me to reflect on the near future. You always have a mental idea of what you want to do and which group you'll feel more comfortable with, but a written reflection always makes you think in a bit more depth.” (Student 8)

"This year, with the activities included in this module, I've realized the importance of your life path when choosing one profession over another. I've also learned to construct genograms, a tool I find very useful (...) I've learned how the type of communication you establish with people or making a bond with them affects your intervention." (Student 9)

Students acknowledge that the course has helped them to analyze complex situations in more depth; they also state that they have learnt to take into account the role subjectivity plays in this analysis and the relationship between one's own 
beliefs and personal experiences and ways of responding and reacting in certain situations:

"I've learned to reflect on the subjectivity which, without realizing it, we tend to employ when interpreting and analyzing a case, and to look for the personal reason that has led me to opt for one position over another. That is, I've become aware of the link that exists between our beliefs and personal experiences and the response and reaction we have to a particular case or situation" (Student 6)

"I've learned to be aware of aspects like when to reveal personal information to users, the importance of protecting ourselves mentally so as to avoid taking users' problems into our own private life; the importance of knowing how to connect with users, that is, using the bond as an essential tool that allows us to work with people and achieve the proposed objectives more easily.“ (Student 10)

However, analyzing these positives does not mean we have lost sight of those aspects which could be improved or represent difficulties and challenges requiring further work. One of the difficulties is related to what many authors have highlighted regarding assessing reflective learning. Different authors point out the difficulties and contradictions inherent in assessing this type of learning (Bolton, 2010; Gursansky et al, 2010; Rai, 2006). Rogers (2001) states that it is not clear how to ensure students have become more reflective or are reflecting more profoundly as a result of the educational experience. Other authors, such as Boud and Walker (1998), seriously question whether reflective learning should be assessed. And when the object of assessment is reflective learning in activities aimed at developing the use of self, the process is even more complex. 
Another difficulty is related to the roles tutors and students adopt within the group. Tutors necessarily have to carry out a critical analysis of their own conceptions of teaching and learning. This means they have to improve their skills of working in a small group and therefore requires theoretical training and practice to help them focus sessions appropriately. The reflective focus requires students make a commitment to learning, develop the will to analyze situations in greater depth, and have an interest and motivation for learning.

On a more concrete level, this course has shown us that managing the atmosphere created within the group is fundamental to the success of the experience. In respect of this, two strategies we rated highly were firstly, organizing activities in such a way as to make the change towards work on more personal issues a gradual one, and secondly, alternating between work on other people's experiences or fictitious situations and reflecting on one's own life and experiences.

Introducing work on use of self in the training of students prior to their work placement in centers and institutions allowed us a more in-depth understanding of how to use reflective methodology in supervising students' work placements on subsequent courses. The students who participated in this experience in 2010-11 began their work placement the following academic year having already reflected on their own experiences, emotions, skills and prejudices. What would be worth analyzing from this point on is the extent to which having participated in the module affects how they approach the challenges of their first professional placement. Our hypothesis is that what they have learnt from this will provide them with further tools for exercising their professional duties from a critical perspective. 
Reflective learning constitutes the core methodology on the University of Girona's Social Education degree course. Training is divided into two phases. During the first two years, students work on competences related to interpersonal communication, teamwork and use of self using both their own personal experiences in the academic environment and everyday life and those of other people. The final two years of the course are based on students' experiences in their practical placement and tutor supervision of the placement. The ultimate aim of this methodology is to help students discover the profession by preparing them to work in contexts of uncertainty and cope with complex situations.

\section{References}

Arandia, M., Fernández, I., Alonso-Olea, M.J., Uribe-Etxebarria, A., Beloki, N., Remiro, A., Aguirre, N. \& Otaño, J. (2012) "Formación y desarrollo professional de los educadores y educadores sociales en el ámbito de la infancia desprotegida: contexto y perspectivas en la comunidad autónoma vasca", Revista de Educación, no 359. DOI: 10-4438/1988-592X-RE-2010-350-105

Bolton, G. (2001) Reflective practice. Writing and professional development, Paul Chapman Publishing, London.

Boud, D. (1999) "Avoiding the traps: seeking good practice in the use of self assessment and reflection in professional courses", Social Work Education, vol.18, no. 2, pp.121-132.

Boud, D. \& Walker, D. (1998) "Promoting reflection in professional courses. The challenge of context", Studies in Higher Education, Vol. 23, no. 2, pp.191-206.

Brockbank, A. \& McGill, I. (1998) Facilitating Reflective Learning in Higher Education, Society for Research into Higher Education and Open University Press, Buckingham.

Chapman, M.V., Oppenheim, S., Shibusawa, T. \& Jackson, H.M. (2004) "What We Bring to Practice: Teaching students about professional Use of Self", Journal of Teaching in Social Work, Vol. 23, no. 3, pp. 3-14.

Dempsey, M., Halton,C. \& Murphy, M. (2001) "Reflective Learning in Social Work Education: Scaffolding the Process, Social Work Education, vol. 20, no. 6, pp. 631641.

Downey, E, Jackson, R.L, Puig, M.E \& Furman, R. (2003) "Perceptions of efficacy in the use of contemporary film in social work education: an exploratory study", Social Work Education, vol. 22, no. 4, pp.401-410 
Fook, J. (2007) "Uncertainly: the defining characteristic of social work?". In Social Work. A Companion to Learning, eds. M. Lymbery \& K. Postle, Sage, London.

Fook, J. White, S. \& Gardner, F.(2006) "Critical reflection: a review of contemporary leterature and understandings", in Critical reflection in Health and Social Care, eds. S. White, J. Fook \& F. Gardner, Open University Press, Glasgow.

Frost, S. (2006) "Recasting individual practice through reflection on narratives", in Critical reflection in Health and Social Care, eds. S. White, J. Fook \& F. Gardner, Open University Press, Glasgow.

Fullana, J., Pallisera, M., Tesouro, M. and Castro, M. (2009) "Professional placement and professional recognition of Social Education graduates in Spain. A ten-year balance", Social Work Education, vol. 28, no. 4, pp. 336-350.

Fullana, J., Serra, C. \& Pallisera, M.(2011) "The social professions in Spain: past and present”, European Journal of Social Education, Vol. 20/21, pp. 34-44.

Gursansky, D., Quinn, D. \& Le Sueur (2010) "Authenticity in Reflection: Building Reflective Skills for Social Work”, Social Work Education, vol. 29, no. 7, pp.778791.

Harrison, K. (2009) "Listen: this Really Happened: Making Sense of Social Work through Story-Telling”, Social Work Education, vol. 28, no. 7, pp. 750-764.

Harrison, K. \& Ruch, G. (2007) "Social work and the use of the self. On becoming and being a social worker", in Social Work. A Companion to Learning, M. Lymbery \& K .Postle, Sage, London, 40-50.

Jenkins, M. \& Londsdale, J. (2007) "Evaluating the effectiveness of digital storytelling for student reflection". Proceedings ascilite Singapore 2007. [online] Avalilable at: $\langle$ http://www.ascilite.org.au/conferences/singapore07/procs/jenkins.pdf $>$ (accessed 28 October 2011).

Kantowicz, E. (2007) "Dilemmas in comparative research of education for social work in Europe", European Journal of Social Work, vol. 8, no. 3, pp. 297-309

Keats, P. (2009) "Multiple text analysis in narrative research: visual, written, and spoken stories of experience". Qualitative Research, vol. 9, pp.181-195.

Knott, C. (2010) Reflective practice revisited. Knott, Ch. \& Scragg, T. (Eds.) Reflective Practice in Social Work. Learning Matters Exeter, 3-12.

Kolb, D.A. (1984) Experiential Learning. Experience as The source of Learning and Development. NJ: Practice-Hall, Englewood Cliffs.

Lehmann, J. (2006) "Telling stories... and the pursuit of critical reflection", in Critical reflection in Health and Social Care, eds. S. White, J. Fook \& F. Gardner, Open University Press, Glasgow.

Liles, R. E. (2007) "The Use of Feature Films as Teaching Tools in Social Work Education", Journal of Teaching in Social Work, vol. 27, no 3, pp. 45-60.

Lordan, N., Quirke, D., \& Wilson, M. (2009) "Mask Making and Social Groupwork", in Strengh and Diversity in Social Work with Groups, eds C.S.Cohen, M.H. Phillips, M.Handon, Routledge, New York \& London. 
McKillop, C. (2005) Storytelling grows up: using storytelling as a reflective tool in higher education. Paper presented at the Scottish Educational Research Association conference (SERA 2005), 24-26 November, 2005, Perth, Scotland

Meeuwisse, A. \& Swärd, H. (2007) "Cross-national comparisons of social work -a question of initial assumptions and level of analysis", European Journal of Social Work, vol. 10, no. 4, pp. 481-496.

Osmond, J. \& Darlington, Y. (2005) "Reflective analysis: Techniques for facilitating reflection", Australian Social Work, Vol. 58, no. 1, pp. 3-14.

Paquin, G. (2006) "Including Narrative Concepts in Social Work Practice Classes. Teaching to Client Strenghts", Journal of Teaching in Social Work, vol. 26, no. 1, pp. $127-145$

Rai, L. (2006) "Owning (up to) Reflective Writing in Social Work Education", Social Work Education, vol. 25, no 8, pp. 785 -797.

Reupert, A. (2009) "Students' Use of Self: Teaching Implications", Social Work Education, vol. 28, no. 7, pp. 765-777.

Rogers, R. R. (2001) "Reflection in Higher Education: A Concept Analysis" Innovative Higher Education, vol. 26, no.1, pp.37-57.

Ruch, G. (2000) "Self and social work: towards an integrated model of learning", Journal of Social Work Practice, Vol. 14, no. 2, pp. 99-111.

Shdaimah, C (2009) "The Power of Perspective: Teaching Social Policy with Documentary Film", Journal of Teaching in Social Work, vol. 29, pp. 85-100.

Taylor, C. (2003) "Narrative practice: reflective accounts and the textual construction of reality", Journal of Advanced Nursing, vol. 42, no. 3, pp. 244-251.

Taylor, C. (2006) "Narrating Significant Experience: Reflective Accounts and the Production of (Self) Knowledge", British Journal of Social Work, vol. 36, pp.189206.

Tomkins, A. (2009) Learning and Teaching Guides, Developing Skills in Critical Reflection Through Mentoring Stories. Higher Education Academy Network for Hospitality, Leisure, Sport and Tourism. [online] Available at: <http://hca.ltsn.ac.uk/assets/hlst/documents/resources/ssg_tomkins_mentoring_stori es.pdf> (accessed 28 October 2011).

Ward, A. (2008) Beyond the instructional mode: creating a holding environement for learning about the use of self, Journal of Social Work Practice, vol. 22, no. 1, pp. 67-83. 